\title{
The Effects of the Emission Cost on Route Choices of International Container Ships
}

\author{
Hyangsook Lee, ${ }^{1}$ Kang-Dae Lee, ${ }^{2}$ and Sangho $\mathrm{Choo}^{3}$ \\ ${ }^{1}$ Graduate School of Logistics, Incheon National University, 12-1 Songdo-dong, Yeonsu-gu, Incheon 406-772, Republic of Korea \\ ${ }^{2}$ Department of Packaging, Yonsei University, 234 Maeji, Heungup, Wonju, Kangwon-do 220-710, Republic of Korea \\ ${ }^{3}$ Department of Urban Design \& Planning, Hongik University, 72-1 Sangsu-dong, Mapo-gu, Seoul 121-791, Republic of Korea
}

Correspondence should be addressed to Sangho Choo; shchoo@hongik.ac.kr

Received 18 December 2015; Accepted 5 May 2016

Academic Editor: Zhimin Huang

Copyright (C) 2016 Hyangsook Lee et al. This is an open access article distributed under the Creative Commons Attribution License, which permits unrestricted use, distribution, and reproduction in any medium, provided the original work is properly cited.

\begin{abstract}
Maritime freight shipping has increased significantly and air pollution from international ships has grown accordingly, having serious environmental effects all over the world. This paper analyzes the effects of the emission cost on ocean route choices, focusing on international container ships. First, the paper formulates a freight network model that captures decisions and interactions of ocean carriers and port terminal operators in the maritime freight transport system. Then, the emission cost is calculated based on an activity-based approach as a component of the ocean transportation cost function. A case study is examined to find if the emission cost affects ocean route choices. The results indicate that the optimal ocean route and transportation cost are changed distinctively due to the emission cost. The research discusses how the emission cost plays a role in route changes and why ocean carriers have to consider these costs in their routing decisions.
\end{abstract}

\section{Introduction}

International freight shipping has been increasing significantly due to the growth of global trades and the following increment in maritime freight transportation. Up to 2008, the growth of world container traffic was a continuous process, with a change from 28.7 million TEUs in 1990 to 152.0 million TEUs in 2008, showing an increase of $430 \%$ (Bureau of Transportation Statistics). Slow economy of 2009-2010 had an impact on container flow, experiencing a drop of 49 million TEUs. However, the container movements have been rising again since 2010.

Nowadays, ocean carriers are regarded as one of the biggest sources of air pollution. International ships are usually powered by diesel engine system which emits major air pollutants such as nitrogen oxides $\left(\mathrm{NO}_{x}\right)$, carbon dioxides $\left(\mathrm{CO}_{2}\right)$, sulfur dioxide $\left(\mathrm{SO}_{2}\right)$, and particulate matters $(\mathrm{PM})$. These are known to have a harmful influence on ship workers and local residents, causing asthma, respiratory disease, cardiac disorder, and so forth. Therefore, as maritime freight shipping has grown rapidly, the air pollution problem has become a serious and urgent issue all over the world.

There has been global effort to regulate air pollution. For example, the Kyoto Protocol that controls global warming gases took effect in 2005. International Maritime Organization (IMO) activated the regulations for air pollution from ships in the same year. Also, advanced countries like Japan, USA, and EU set the emission standard and tightened the control of air pollution caused from big ships and ports. In addition, some dominant ocean shipping companies started to consider the environment cost when transporting goods in aspects of environment-friendly company image and social contribution.

Carriers are transportation service providers in the freight transportation network. A set of carriers includes ocean carriers, land carriers, and port terminal operators. In general, particularly in the common case of a landlord port, a Port Authority leases marine terminals to private terminal operators. Port terminal operators offer the transportation service in port complex as a special type of carrier. Ocean 
carriers typically choose departure and arrival marine ports in a cost-efficient manner. Therefore, ocean carriers are regarded as leaders and port terminal operators are followers in the maritime freight shipping market.

Carriers are also private transportation companies that attempt to maximize their profits; therefore they determine delivery routes (service processes) by minimizing the transportation cost that contains the operating cost, the travel time, and so forth. If the environmental cost is considered in the transportation cost function, their optimal route choices may be changed. This paper examines the effects of the emission cost on the routing pattern, concentrating on the emissions of container ships. For the emission cost estimation of ocean-going vessels, an activity-based approach is employed.

The structure of the paper is as follows. The next section presents an up-to-date literature review of the existing freight network models and relevant studies on the environmental cost. Section 3 defines carrier network structures and modeling approaches. Section 4 formulates a bilevel model that captures hierarchical interactions between ocean carriers and port terminal operators. Section 5 develops an algorithm to solve the bilevel model. Next, a numerical example is deployed to demonstrate the validity of the model and to analyze changes caused by the emission cost in optimal ocean routes and port operations.

\section{Literature Review}

Lots of works capturing decisions and relationships of key stakeholders (i.e., producers, consumers, shippers, carriers, and governments) involved in land transportation have been done. Regarding the seaborne freight network problem, relatively a small amount of literature exists. Zan [1], Kuroda et al. [2], and Zhang et al. [3] considered interactions between shippers and ocean carriers or port terminal operators, assuming decisions of the other carriers are given. Lee et al. $[4,5]$ presented hierarchical relationships among three types of carriers focusing on the different carrier problem in both competitive and cooperative markets. Lee et al. [6] captured interactions between shippers and three types of carriers by considering one more key stakeholder. Wang [7] and Min and Guo [8] developed more complicated mathematical models adding another major decision maker, Port Authority. These studies used equilibrium concepts (e.g., user equilibrium, Nash equilibrium, spatial price equilibrium, or compensation principle) to analyze the behavior of individual stakeholder groups. For multilevel games, Stackelberg game or multileader-follower game frequently was applied. Zhang et al. [9] explored competitive, cooperative, and Stackelberg congestion pricing for local regions. Practical pricing schemes between different administrative regions were presented employing both Nash game and Stackelberg game. On the other hand, G. S. Kim and T. S. Kim [10] presented cooperative development of logistics systems through the functional networking of port cities. The paper showed the allocation of logistics function and cooperative networking in logistics systematically and horizontally.
Several works have focused on environmental issues in the freight network problems. Jiang and Kronbak [11] presented a good summary of major research on estimating the external costs of maritime transportation and defined a generalized form of the voyage-based model. Berechman and Tseng [12] studied the emission cost of ships and trucks for eight main air pollutants in the Port of Kaohsiung, Taiwan. A bottom-up methodology was employed defining the engine load, load factor, and emission factor. Over 123 million dollars per year was estimated, indicating that tankers, container ships, bulk ships, and trucks are major contributors causing environmental problems. Yau et al. [13] developed a detailed maritime emission inventory for ocean-going vessels in Hong Kong. A bottom-up activity-based approach was adopted to estimate the emissions from main and auxiliary engines and boilers. Containers ships contributed over $70 \%$ of the total emissions of $\mathrm{NO}_{x}, \mathrm{SO}_{2}$, and $\mathrm{PM}_{10}$. Saraçoğlu et al. [14] investigated the effects of ship sourced emission in Izmir Port, Turkey. Exhaust gas emissions from ships in the port were calculated by adopting a ship activity-based methodology. Total emissions of $\mathrm{NO}_{x}, \mathrm{SO}_{2}, \mathrm{CO}_{2}, \mathrm{HC}$, and $\mathrm{PM}$, classified according to operation modes and ship types, were estimated and compared with relevant study results. Deniz et al. [15] studied maritime shipping emissions in Candarli Gulf, Turkey. Various emissions were calculated based on the activity-based emission model in Aliaga Bay and Nemrut Bay. Corbett et al. [16] discussed the effectiveness of the speed reduction on emissions for international shipping. By applying a profit-maximizing function that corporates the opportunity cost to estimate route-specific, economically efficient speeds, policy impacts of a fuel tax and a speed reduction mandate on $\mathrm{CO}_{2}$ emissions were explored. On the other hand, Ahn and Rakha [17] investigated the effects of route choice decisions on vehicle energy consumption and emission rate for different types of vehicles using some emission estimation tools. Research results demonstrated that the faster route choice is not always the best from an environmental or energy consumption perspective. Park et al. [18] estimated trade-off relationships among logistics cost, time, and $\mathrm{CO}_{2}$ emissions of the freight transportation system in Korea. The trade-off relationships between attributes were clearly shown and the desired level of modal split of intermodal freight transportation system was identified. Shukla and Alam [19] focused on the interaction between the vehicle emissions like $\mathrm{NO}_{x}, \mathrm{HC}, \mathrm{CO}$, and $\mathrm{CO}_{2}$ and traffic control measures. Results showed that high emission rates occurred during acceleration and delay events, while vehicle emissions were relatively low when the vehicle was idling.

In summary, most former studies focused on interactions between key stakeholders in the freight network problem. Some works estimated emissions and emission costs of trucks, vessels, or port sites, respectively. On the other hand, this research combined two issues, freight network problem and environmental problem. The paper formulates a freight network model capturing ocean carriers' optimal routing choices in determining marine ports using bilevel optimization programming. Here, the environmental cost is considered as a factor of the ocean transportation cost 
function to demonstrate the effects of the emission cost on routing decisions by employing an activity-based approach.

\section{Problem Definition}

3.1. Network Structure. The carrier network is a physically detailed multimodal network that shows transportation routes and modes. Three types of networks, the marine transport network, the port network, and the land transport network, are defined for the maritime freight transportation problem. Links in the ocean and land transport networks represent alternative delivery routes and links in the port network express different port service processes such as loading, unloading, moving, and storing. The ocean transport network includes port-entrance links to access port terminals and the land transport network contains port-exit links to egress from port terminals. Figure 1 depicts a general carrier network and Figure 2 shows samples of port networks.

3.2. Assumptions. Basic assumptions for the definiteness and simplicity of modeling are presented as follows:

(1) Freight is shipped from a departure port terminal via an arrival port terminal to a land destination, assuming that commodities are produced near the departure port terminal.

(2) Ocean carriers choose port terminals of the alternative ones located in competitive regions.

(3) Multiple ocean carriers and port terminal operators have independent operations without cooperation in the competitive market environment.

3.3. Modeling Approach. Ocean carrier objective function is a cost minimization function. Ocean carriers departing a port terminal choose one of the arrival port terminals by considering the operating cost and the travel time on the transportation network as well as other determinants such as the port location and the port service charge. In particular, this research considers the emission cost in order to analyze the environmental effect on making ocean route choices. The port terminal operator objective function is a profit maximization function. Port terminal operators suggest competitive and reasonable service charges to attract more ocean liners and they simultaneously aim to minimize port service costs in the port complex. Therefore, ocean carriers are the leaders and port terminal operators are the followers.

At the first level, the ocean carrier problem is formulated using user equilibrium. User equilibrium finds the optimal ocean routes for which each ocean carrier obtains the lowest transportation in the competitive market environment. At the second level, the port terminal operator problem is formulated using Nash equilibrium. Nash equilibrium finds the optimal service charge and port service pattern for which each port terminal operator obtains the greatest profit in the competitive market environment.

Hierarchical interactions between ocean carriers and port terminal operators are captured employing a bilevel optimization programming. The concept of multi-leaderfollower game is applied to a bilevel game, assuming the multiple and competitive leaders. Port service charges affect ocean carriers' routes, while port throughputs are influenced by ocean carriers' routing decisions.

3.4. Emission Cost. In this study, an activity-based maritime emission is employed. The emission cost for sailing between marine ports is calculated based on the vessel speed and sailing time. The total amount of emissions is estimated first and then transformed into money value by applying the unit emission cost according to the type of air pollutant.

For the main engine, emissions were estimated by using the following generic equation [20]:

$$
\mathrm{E}=P \times \mathrm{LF} \times A \times \mathrm{EF},
$$

where $\mathrm{E}$ is emission from engine $(\mathrm{g}), P$ is engine power $(\mathrm{kW})$, LF is engine load factor, $A$ is ship activity (h), and EF is emission factor $(\mathrm{g} / \mathrm{kW}-\mathrm{h})$.

Data on engine power ratios, engine load power, and emission factor were derived from literature. Table 1 illustrates main and auxiliary engine power ratios for six types of ships, ranging from 0.191 to 2.789 . The main engine power ratio of the container is 0.220 , showing a relatively small number. Load factors for four types of ship operations are defined in Table 1.

Emission factors are different according to the air pollutant and sailing speed. Emission factors for three speed categories (high, medium, and low) and three major air pollutants $\left(\mathrm{NO}_{x}, \mathrm{SO}_{2}\right.$, and $\left.\mathrm{PM}_{10}\right)$ are shown in Table 2 . The emission of $\mathrm{NO}_{x}$ is the greatest, while $\mathrm{PM}_{10}$ is the smallest, indicating a significant difference. The speed change influences both $\mathrm{NO}_{x}$ and $\mathrm{PM}_{10}$, although the direction of the correlation is opposite.

Meanwhile, activity time implies the sailing duration for ships on major routes. Activity time data can be created by obtaining vessel speed profiles and distances between marine ports.

\section{Mathematical Formulations}

4.1. Ocean Carrier Problem. Ocean carriers provide transportation services between marine ports via waterways. They compete with others to choose marine terminals in a costefficient manner.

4.1.1. Equilibrium Condition. User equilibrium is used to find the optimal routing pattern for which each ocean carrier obtains the lowest transportation cost. Each user noncooperatively attempts to minimize his cost of transportation. No ocean carrier may lower his transportation cost by having unilateral action in equilibrium:

$$
\mathrm{TC}_{w}^{o}\left(f_{w}^{o *}\right) \leq \mathrm{TC}_{w}^{o}\left(f_{w}^{o}\right) \quad \forall o \in O, w \in W .
$$

Equation (2) implies that if ocean carrier $o$ for $O-D$ pair $w$ changes his routing choices from optimal to any other feasible decisions when other ocean carriers keep their routes constant, the transportation cost will increase. 


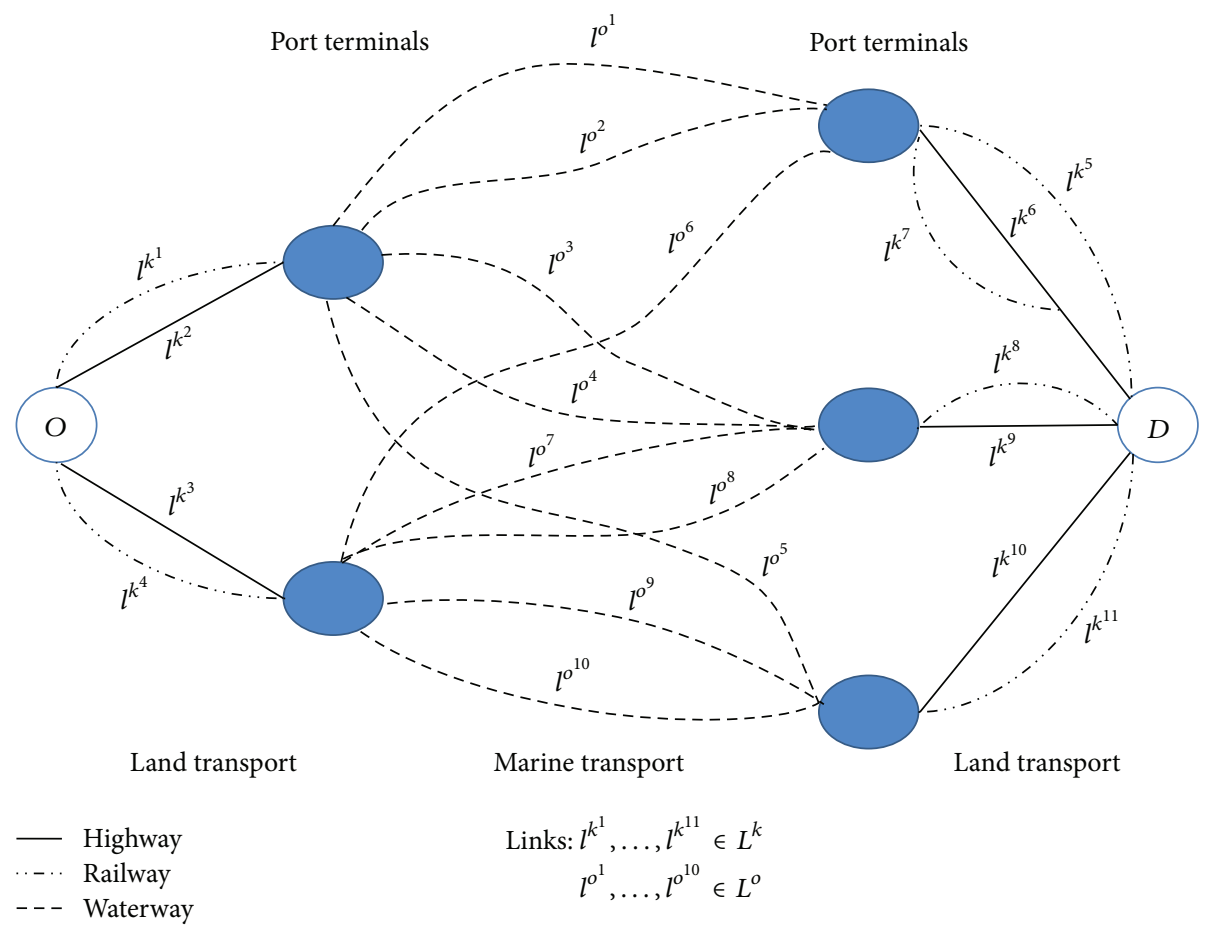

FiguRE 1: Carrier network.

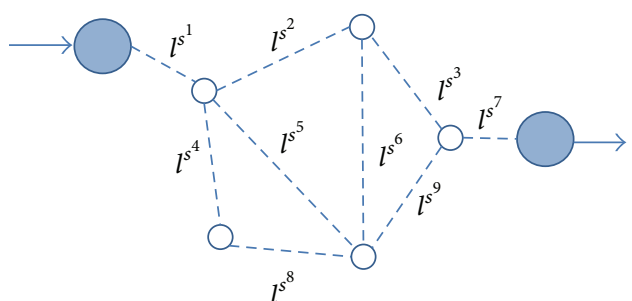

Port terminal 1

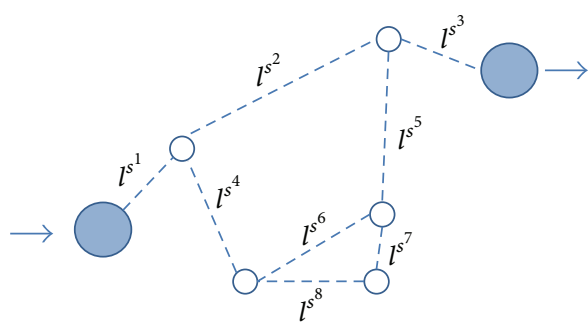

Port terminal 2

-- Port operations Links: $l^{s^{1}}, \ldots, l^{s^{9}} \in L^{s}$

Figure 2: Port network (samples).

4.1.2. Objective Function. The objective function is a cost minimization function. Each ocean carrier aims to minimize the transportation cost by maximizing the revenue and minimizing the transportation cost:

$$
\min \quad \mathrm{TC}_{w}^{o}=\sum_{p^{o}}^{P^{o}} \sum_{p^{o}}^{P^{o}} \mathrm{TC}_{w}^{p^{o}}\left(f_{w}^{p^{o}}\right) f_{w}^{p^{o}} \quad \forall o \in O, w \in W
$$

Equation (3) represents the transportation cost function decided by the transportation cost function depending on the flow on all used ocean paths.

4.1.3. Assumptions for the Objective Function. The ocean path transportation cost function is a linear combination of the following three attributes: (a) the sum of ocean link transportation cost functions if the ocean link is on the path, (b) the sum of emission costs, and (c) the sum of port service charges if ocean carrier $o$ chooses port terminal operator $s$. The emission cost on the ocean path is calculated based on the vessel speed (Tables 1 and 2) and sailing time (obtained from vessel speed profiles and distances marine ports) according to the type of air pollutant:

$$
\begin{aligned}
\operatorname{TC}_{w}^{p^{o}}\left(f_{w}^{p^{o}}\right)= & \sum_{l^{o}}^{L^{o}} \mu_{w}^{l^{o}, p^{o}} \operatorname{TC}^{l^{o}}\left(f^{l^{o}}\right)+\mathrm{EC}_{w}^{p^{o}} f_{w}^{p^{o}} \\
& +\pi^{o, s} c^{s} f_{w}^{p^{o}} \quad \forall w \in W, p^{o} \in P_{w}^{o}, s \in S
\end{aligned}
$$

If the ocean link is on the ocean path for $O-D$ pair $w$, $\mu_{w}^{l^{o}, p^{o}}$ is 1 ; otherwise, it is 0 . If ocean carrier $o$ chooses port terminal operator $s, \pi^{o, s}$ is 1 ; otherwise, it is 0 . The ocean link transportation cost function comprises (a) the average ocean link operating cost function and (b) the average ocean link 


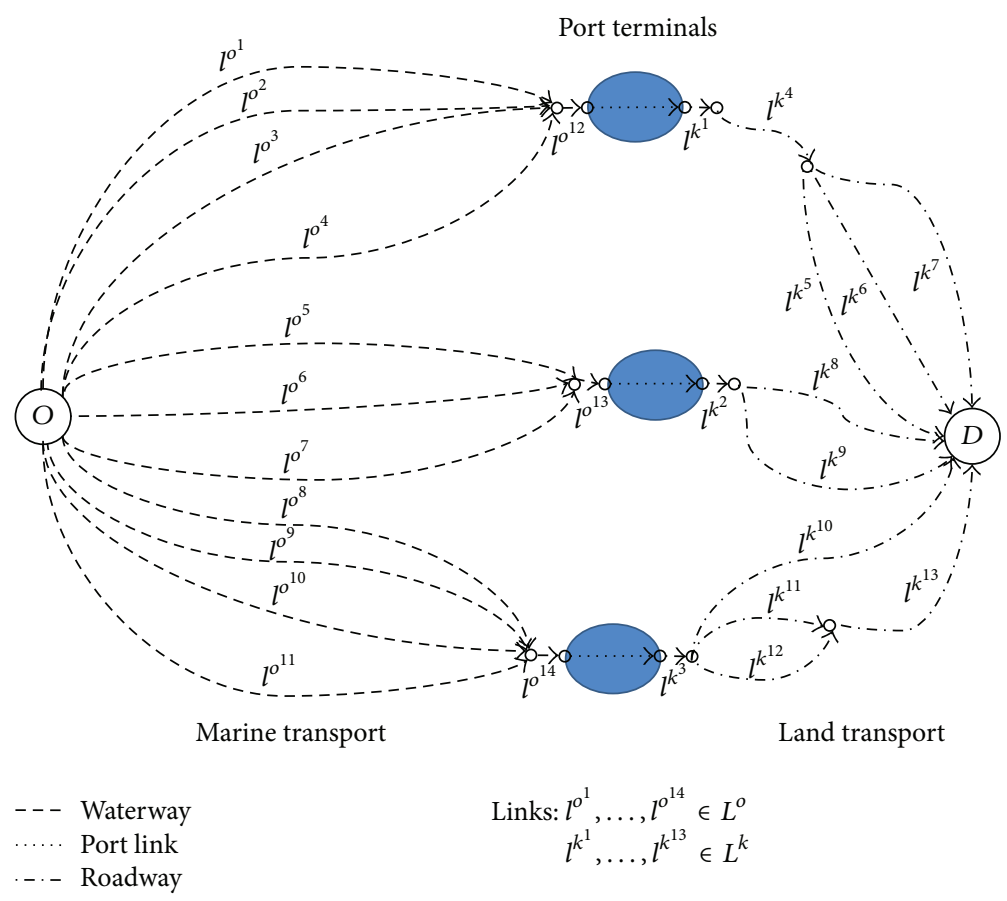

FIgURE 3: Carrier network in the example.

travel (shift) time function. The travel (shift) time is changed to money using value of time:

$$
\operatorname{TC}^{l^{o}}\left(f^{l^{o}}\right)=\operatorname{OC}^{l^{o}}\left(f^{l^{o}}\right) f^{l^{o}}+\operatorname{vot}^{o} \operatorname{TT}^{l^{o}}\left(f^{l^{o}}\right) f^{l^{o}}
$$

$$
\forall l^{o} \in L^{o}
$$

where

$$
\begin{aligned}
& \operatorname{OC}^{l^{o}}\left(f^{l^{o}}\right)=\omega_{o}+\omega_{1}\left[\frac{f^{l^{o}}}{\operatorname{cap}^{l^{o}}}\right]+\omega_{2}\left[\frac{f^{l^{o}}}{\operatorname{cap}^{o^{o}}}\right]^{2} \\
& \forall l^{o} \in L^{o}, \\
& \operatorname{TT}^{l^{o}}\left(f^{l^{o}}\right)=\mathrm{tt}^{l^{o}}+\mathrm{st}^{l^{o}}\left[1+\varepsilon_{o}\left(\frac{f^{l^{o}}}{\operatorname{cap}^{l^{o}}}\right)\right]^{\varepsilon_{1}} \quad \forall l^{o} \in L^{o} .
\end{aligned}
$$

The average operating cost and travel (shift) time functions are assumed to be continuous and strictly monotone increasing in the flow.

4.1.4. Feasible Region of the Objective Function. The feasible region of the ocean carrier objective function (OFR) is defined by linear equality and nonnegativity constraints:

$$
\begin{aligned}
& \sum_{o}^{O} d_{w}^{o}=\sum_{p^{o}}^{P^{o}} f_{w}^{p^{o}} \quad \forall w \in W, \\
& f_{w}^{p^{o}} \geq 0 \quad \forall o \in O, w \in W .
\end{aligned}
$$

Equation (7) ensures that the sum of individual ocean carrier service demands for $O-D$ pair $w$ is equivalent to the sum of ocean carrier flows on all used ocean paths. These linear equality constraints define a closed and convex feasible region. Equation (8) states nonnegativity of ocean container flow.

4.1.5. Mathematical Formulation. For the ocean carrier problem, the research adopts a container transport network equilibrium model proposed by Zhang et al. [3]. As a modeling methodology, variational inequality by Nagurney [21] was adopted:

$$
\begin{aligned}
& \mathrm{TC}_{w}^{p^{o} *}-\mathrm{MC}_{w}^{*}= \begin{cases}=0 & f_{w}^{p^{o} *}>0 \\
\geq 0 & f_{w}^{p^{o} *}=0\end{cases} \\
& \forall p^{o} \in P_{w}^{o}, \forall w \in W
\end{aligned}
$$

where $\mathrm{MC}_{w}^{*}$ denotes the minimum path cost between $O-D$ pair $\omega$ in equilibrium, $f_{w}^{p^{o} *}$ represents the container volume of ocean path $p$ in equilibrium, and $\mathrm{TC}_{w}^{p^{o} *}$ represents the total transportation cost in equilibrium.

Theorem 1. The necessary and sufficient condition of $f^{*}$ as the equilibrium solution of (9) is that $f^{*}$ is the solution of the following variation inequality:

$$
\sum_{w}^{W} \sum_{p^{o}}^{P_{w}^{o}}\left(T C_{w}^{p^{o} *}-M C_{w}^{*}\right)\left(f_{w}^{p^{o}}-f_{w}^{p^{o} *}\right) \geq 0 .
$$

Proof. First, verify sufficiency.

$\forall w \in W, p^{o} \in P_{w}^{o}$, if $f_{w}^{p^{*} *}=0$, then, based on (9), we have the following: $\forall f_{w}^{p^{o}} \geq 0,\left(\mathrm{TC}_{w}^{p^{o} *}-\mathrm{MC}_{w}^{*}\right)\left(f_{w}^{p^{o}}-f_{w}^{p^{o} *}\right)=$ 
$\left(\mathrm{TC}_{w}^{p^{o} *}-\mathrm{MC}_{w}^{*}\right) f_{w}^{p^{o}} \geq 0$; if $f_{w}^{p^{o} *}>0$, according to (9), we have $\mathrm{TC}_{w}^{p^{o} *}-\mathrm{MC}_{w}^{*}=0 ; \forall f_{w}^{p^{o}} \geq 0$, we have $\left(\mathrm{TC}_{w}^{p^{o} *}-\mathrm{MC}_{w}^{*}\right)\left(f_{w}^{p^{o}}-\right.$ $\left.f_{w}^{p^{o} *}\right)=0$. So $\left(\mathrm{TC}_{w}^{p^{o}{ }^{*}}-\mathrm{MC}_{w}^{*}\right)\left(f_{w}^{p^{o}}-f_{w}^{p^{o} *}\right) \geq 0$. At the same time, $\forall w \in W, p^{o} \in P_{w}^{o},\left(\mathrm{TC}_{w}^{p^{o} *}-\mathrm{MC}_{w}^{*}\right)\left(f_{w}^{p^{o}}-f_{w}^{p^{o} *}\right) \geq 0$, so $\sum_{w}^{W} \sum_{p^{o}}^{P^{o}}\left(\mathrm{TC}_{w}^{p^{o} *}-\mathrm{MC}_{w}^{*}\right)\left(f_{w}^{p^{o}}-f_{w}^{p^{o} *}\right) \geq 0$.

Second, verify necessity.

Taking $k \in W, d \in P_{k}$ and $\forall w \in W \backslash k, p^{o} \in P_{w}^{o}, p^{o} \in$ $p_{k}^{o} \backslash d$, let $f_{w}^{p^{o}}-f_{w}^{p^{o} *}$; then $(10)$ is changed to $\left(\mathrm{TC}_{k}^{d *}-\mathrm{MC}_{k}^{*}\right)\left(f_{k}^{d}-\right.$ $\left.f_{k}^{d *}\right) \geq 0 \forall f_{k}^{d} \geq 0$, so, for all $k \in W, p \in P_{\omega}$, if $f_{k}^{d *}=0$, then $\mathrm{TC}_{k}^{d *}-\mathrm{MC}_{k}^{*} \geq 0$; if $f_{k}^{d *}>0$, then $\mathrm{TC}_{k}^{d *}-\mathrm{MC}_{k}^{*}=0$. Obviously, (10) is proved.

Equation (9) can be transformed into the following formula:

$$
\begin{aligned}
& \sum_{w}^{W} \sum_{p^{o}}^{P_{w}^{o}} \mathrm{TC}_{w}^{p^{o} *}\left(f_{w}^{p^{o}}-f_{w}^{p^{o} *}\right)-\sum_{w}^{W} \sum_{p^{o}}^{P_{w}^{o}} \mathrm{MC}_{w}^{*}\left(f_{w}^{p^{o}}-f_{w}^{p^{o} *}\right) \\
& \quad \geq 0
\end{aligned}
$$

According to flow conservation law, the above formula is changed to

$$
\begin{aligned}
& \sum_{w}^{W} \sum_{p^{o}}^{P_{w}^{o}} \mathrm{TC}_{w}^{p^{o} *}\left(f_{w}^{p^{o}}-f_{w}^{p^{o} *}\right)-\sum_{w}^{W} \sum_{p^{o}}^{P_{w}^{o}} \mathrm{MC}_{w}^{*}\left(d_{w}^{p^{o}}-d_{w}^{p^{o} *}\right) \\
& \quad \geq 0
\end{aligned}
$$

The vector form is

$$
\mathrm{TC}\left(f^{o *}\right)^{T}\left(f^{o}-f^{o *}\right)-M^{* T}\left(g-g^{*}\right) \geq 0 .
$$

Assuming that the demand of $O-D$ is fixed, (13) becomes $\mathrm{TC}\left(f^{o *}\right)^{T}\left(f^{o}-f^{o *}\right) \geq 0$.

According to the relation between transportation arc and transportation path, the above variational inequality is expressed as

$$
\mathrm{TC}\left(f^{o *}\right)^{T}\left(f^{o}-f^{o *}\right) \geq 0
$$

4.2. Port Terminal Operator Problem. Port terminal operators provide the transportation service for freight arriving in the port complex. The port service charge affects ocean carriers' routes, while port throughputs are influenced by ocean carriers' routing decisions.

4.2.1. Equilibrium Condition. Nash equilibrium is used to find the optimal port service charge and pattern for which each port terminal operator obtains the greatest profit. No port terminal operator can be better off by changing its decisions unilaterally in equilibrium. Consider

$$
U^{s}\left(c^{s *}, c^{-s *}, f^{s *}\right) \geq U^{s}\left(c^{s}, c^{-s *}, f^{s}\right) \quad \forall s \in S .
$$

4.2.2. Objective Function. The objective function is a profit maximization function. Each port terminal operator aims to maximize the profit by maximizing the port revenue and minimizing the port service cost. Consider

$$
\begin{aligned}
& \max U^{s}=\underbrace{G^{s}\left(c^{s}, \overline{c^{-s}}\right) c^{s}}_{R^{s}}-\underbrace{\sum_{v} \sum_{p^{s}}^{P^{s}} \mathrm{SC}_{v}^{p^{s}}\left(f_{v}^{p^{s}}\right) f_{v}^{p^{s}}}_{S C^{s}} \\
& \forall s \in S \text {. }
\end{aligned}
$$

Equation (16) expresses that the profit function of port terminal operator $s$ is composed of the revenue function and the port service cost function. The port terminal operator $s$ is determined by the port throughput depending on the service charge, while other terminal operators keep their current level of service charges constant. The port service cost is decided by the port service cost function depending on the flow on all used port paths.

4.2.3. Assumptions for the Objective Function. The port throughput function of port terminal operator $s$ is assumed to be linear and strictly monotone decreasing in the port service charge:

$$
R^{s}=\beta_{0}-\beta_{1} c^{s} \quad \forall s \in S .
$$

The port path service cost function is the sum of port link service cost functions if the port link is on the path:

$$
\operatorname{SC}_{v}^{p^{s}}\left(f_{v}^{p^{s}}\right)=\sum_{l^{s}}^{L^{s}} \varphi_{v}^{l^{s}, p^{s}} \mathrm{SC}^{l^{s}}\left(f^{l^{s}}\right) \quad \forall v \in V, p^{s} \in P^{s}
$$

The port link service cost function includes the following two attributes: (a) the average port link operating cost function and (b) the average port link service time function. These functions are assumed to be continuous and strictly monotone increasing in the flow. Consider

$$
\begin{aligned}
\operatorname{SC}^{l^{s}}\left(l^{s}\right)=\operatorname{SC}^{l^{s}}\left(f^{l^{s}}\right) f^{l^{s}}+\operatorname{vot}^{s} \operatorname{ST}^{l^{s}}\left(f^{l^{s}}\right) f^{l^{s}} & \\
& \forall l^{s} \in L^{s} .
\end{aligned}
$$

Hessian matrix (second derivatives of the objective function) is negative definite and symmetric. Hence, the objective function is strictly concave in $\left(c^{s *}, f_{v}^{p^{s *}}\right)$.

4.2.4. Feasible Region of the Objective Function. The feasible region of the port terminal operator objective function (PFR) is defined by linear equality and nonnegativity constraints. Consider

$$
\begin{aligned}
& \sum_{w}^{W} \sum_{p^{o}}^{P_{w}^{o}} \pi_{w}^{p^{o}, s} f_{w}^{p^{o}}=G^{s}=\sum_{v}^{V} \sum_{p^{s}}^{P^{s}} f_{v}^{p^{s}} \quad \forall s \in S, \\
& S c^{s}<c^{s}<B c^{s} \quad \forall s \in S, \\
& v^{s}, f_{v}^{p^{s}} \geq 0 \quad \forall s \in S, v \in V, p^{s} \in P^{s} .
\end{aligned}
$$


Equation (20) ensures that the total amount of freight transported via ocean paths is equivalent to the throughput of the port terminal operator $s$ when ocean paths are connected to the port terminal. Also, the throughput is equivalent to the sum of port flows on all used paths in a port complex. Equation (21) ensures that the port service charge ranges from a small number to a large number. Equation (22) states nonnegativity of the port service charge and container flow.

4.2.5. Mathematical Formulation. Based upon the objective function properties and feasible region, a port terminal operator model is formulated by a variational inequality problem. In the competitive game, port terminal operator $s$ finds the optimal service charge and port service pattern to obtain the maximum profit. For a new port service charge, the port revenue and the port service cost are updated to compare the profit. Each port terminal operator attempts to minimize the total port service cost. Thus, port terminal operator $s$ exhibits a system equilibrium-like behavior with the marginal transportation cost function. A port terminal operator model is expressed as follows:

$$
\begin{array}{r}
-\sum_{s}^{S}\left(G^{s}\left(c^{s *}, \overline{c^{-s *}}\right) c^{s *}-S C^{s}\right)\left(c^{s}-c^{s *}\right) \geq 0, \\
\text { where } \sum_{v}^{V} \sum_{p^{s}}^{P^{s}} \nabla_{f} S C_{v}^{p^{s}}\left(f_{v}^{p^{s *}}\right)\left(f_{v}^{p^{s}}-f_{v}^{p^{s} *}\right) \geq 0, \\
\forall\left(c^{s}, f^{s}\right) \in \text { PFR. }
\end{array}
$$

The vector form is

$$
\begin{array}{r}
-\left(G^{s}\left(c^{s *}, \overline{c^{-s *}}\right) c^{s}-\mathrm{SC}^{s}\right)^{T}\left(c^{s}-c^{s *}\right) \geq 0, \\
\text { where } \nabla \operatorname{SC}\left(f^{s}\right)^{T}\left(f^{s}-f^{s *}\right) \geq 0 .
\end{array}
$$

4.2.6. Existence and Uniqueness of the Solution. The formulations above are continuous and linear equality constraints of PFR define a closed convex feasible region. Hence, the existence of the solution is proved. The port terminal operator game has a solution when $c^{s *}, f^{s *}$ satisfy $\left\|c^{* *}, f^{s *}\right\|<R$. The service charge $\left(c^{s}\right)$ is bounded in (21); therefore the port throughput $\left(G^{s}\right)$ is also bounded. With the bounded $G^{s}$, the flow $\left(f^{s}\right)$ is bounded due to the flow conservation constraint in (20). The formulations are strictly monotone in $\left(c^{s}, f^{s}\right)$ from the concave properties of the objective function. Therefore, the solution is unique.

4.3. Bilevel Model. A bilevel model is formulated to capture hierarchical interactions of ocean carriers and port terminal operators when ocean carriers are the leaders and port terminal operators are the followers in the maritime freight transport system. Equation (25) shows a vector form of the bilevel model as follows:

$$
\begin{gathered}
\operatorname{TC}\left(f^{o *}\right)^{T}\left(f^{o}-f^{o *}\right) \\
\text { s.t. }-\left(G^{s}\left(c^{s *}, \overline{c^{-s *}}\right) c^{s}-\mathrm{SC}^{s}\right)^{T}\left(c^{s}-c^{s *}\right) \geq 0,
\end{gathered}
$$

$$
\text { where } \nabla \operatorname{SC}\left(f^{s}\right)^{T}\left(f^{s}-f^{s *}\right) \geq 0, \forall\left(c^{s}, f^{s}\right) \in \operatorname{PFR} \text {. }
$$

\section{Solution Algorithms}

Algorithms are developed to solve the bilevel model using the extra gradient algorithm, an improved version of the projection algorithm, which resolves a variational inequality problem into a sequence of subproblems by the general iterative scheme. Ocean carriers examine the reactions of port terminal operators for feasible scenarios and finally choose the best one which gives the minimum transportation cost. Individual carrier problems are solved in the following steps.

\subsection{Ocean Carrier Problem}

Step 0. Define the initial ocean path flow $f_{w}^{p^{00}}=f_{w}^{p 1^{0}}+f_{w}^{p 2^{o}}+$ $f_{w}^{p 3^{\circ}}+\cdots+f_{w}^{p m^{o}}$ for $O-D$ pair $w$. Let $u$ denote the order of ocean path $f_{w}^{p^{o}}$. Let $z$ denote the order of the iterations. Set $u:=1, z:=1$, and $\sigma_{1}$ is a preset tolerance.

Step 1. Determine $f_{w}^{p^{o}}$ for $u$ th ocean path. Then, decide the next ocean path flow by setting $u:=u+1$ until $u<m$. If $\left|f_{w}^{p 1, z}-f_{w}^{p 1, z-1}\right|<\sigma_{1},\left|f_{w}^{p 2, z}-f_{w}^{p 2, z-1}\right|<\sigma_{1}, \ldots, \mid f_{w}^{p 3, z}-$ $f_{w}^{p 3, z-1} \mid<\sigma_{1}$, stop and denote the solution as $\left(f_{w}^{p m^{o} *}\right)$.

\subsection{Port Terminal Operator Problem}

Step 0. Define the initial port terminal operator service charge $c^{s 0}=c^{s 1}, c^{s 2}, \ldots, c^{s n}$ and flow $f_{w}^{p^{s}}=f_{w}^{p^{s 1}}+f_{v}^{p 1^{s 2}}+$ $f_{v}^{p 1^{s 3}}+\cdots+f_{v}^{p m^{s n}}$. Let $g$ denote the order of port terminal operator $s$ and let $u$ denote the order of port path $f_{v}^{p^{s}}$. Let $x$ and $z$ denote the order of the iterations, respectively. Set $g:=1, u:=1, x:=1$, and $z:=1 . \sigma_{2}$ and $\sigma_{3}$ are preset tolerances.

Step 1. Determine $c^{s}$ for $g$ th port terminal operator with $\overline{c^{-s}}=$ $c^{-s, x-1}$ for the port service demand determined by ocean carriers' routing decisions.

Step 2. Determine $f_{v}^{p^{s}}$ for $u$ th port path of $g$ th port terminal operator. Then, decide the next port path flow by setting $u:=$ $u+1$ until $u<m$. If $\left|f_{v}^{p 1, z}-f_{v}^{p 1, z-1}\right|<\sigma_{2},\left|f_{v}^{p 1, z}-f_{v}^{p 1, z-1}\right|<$ $\sigma_{2}, \ldots,\left|f_{v}^{p m, z}-f_{v}^{p 1, z-1}\right|<\sigma_{2}$, stop and go to Step 3; otherwise, $z:=z+1$ and repeat Step 2 .

Step 3. Solve the next port terminal operator problem via Steps 1 and 2, by setting $g:=g+1$ until $g<n$. 
Step 4. If profit differences of port terminal operators are smaller than $\sigma_{3}$, stop and denote solutions as $c^{s *}, f_{v}^{p^{s *}}$; otherwise, set $x:=x+1$ and turn to Step 1 .

\section{Numerical Example}

A multimodal carrier network is tested using MATLAB R2010a (Pentium IV $3.00 \mathrm{GHz}$ CPU with $8.00 \mathrm{~GB}$ of RAM). The carrier network in the example has 45 links including 14 ocean links $\left(l^{0^{1}} \sim l^{0^{14}}\right), 18$ port links $\left(l^{s^{1}} \sim l^{1^{18}}\right)$, and 13 land links $\left(l^{k^{1}} \sim l^{k^{13}}\right)$. Individual carrier groups provide transportation services at different parts of the carrier network. Freight is shipped from a departure port terminal via an arrival port terminal to a destination, assuming that commodities are produced near the departure port terminal. Ocean carriers that depart a port terminal choose arrival port terminals near a final inland destination by considering the transportation cost, the port location, and the port service cost. Three alternative $O-D$ pairs between marine ports exist in this example. Three port terminal operators located in a competitive region provide port transportation services in the port complex separately. Links in the port network express different port service processes. Land carriers deliver freight from three port terminals to a destination via trucks and rails. Land carrier problem is beyond the study scope. Each port terminal has its own subnetwork according to the port layout and service process. The carrier network is shown in Figure 3.

The total maritime transportation demand is assumed to be 150,500 TEUs during a time period. Multiple ocean carrier companies aim to minimize their transportation costs. In particular, the research analyzes the effects of the emission cost on carrier route choices as seriousness of air pollution and the global concern in the environmental problem increase rapidly. The emissions on ocean path were estimated by multiplying emission components like engine, engine power, engine load factor, ship activity, and emission factor for the three main pollutants of $\mathrm{NO}_{x}, \mathrm{SO}_{2}$, and $\mathrm{PM}_{10}$ and transformed into money value by applying the unit emission cost. Input data were obtained from various references. In order to estimate the emission cost of each container, the maximum ship capacity is assumed to be 15,000 TEUs. Emission costs are calculated to be $\$ 232.8 \sim$ $\$ 241.6$ on ocean links. Table 3 shows parameters in the ocean link operating cost and travel (shift) time functions.

Port terminal operators compete with each other to attract more ocean carriers and attempt to minimize the port service cost with a system equilibrium-like behavior. Port service charge ranges from $\$ 300$ to $\$ 400$ per a unit of freight due to ocean shipping market circumstances. Table 4 shows parameters in the port link operating cost and service time functions. The land transportation cost is assumed to be given in the example.

Table 5 shows container flow changes in ocean links without/with considering the emission costs in the ocean transportation cost. The result indicates how the optimal ocean route decisions are changed by adding the emission costs. The transportation cost at any ocean path is equivalent at $\$ 609$ and $\$ 848$, respectively.

Port throughputs are determined by ocean carriers' routing decisions. Based on the relationships, port profits were also changed by the emission costs. Port terminal operator 2 experienced profit growth, while opposite patterns occur for port terminals 1 and 3. Table 6 shows profit changes of port terminal operators.

The container flow is influenced by port throughputs since port terminal operators attempt to minimize the total port service cost in the current port infrastructure. Table 7 illustrates container flow changes in port links at each port terminal. The marginal transportation cost at any ocean path is equivalent to \$206 and \$205 at port terminal 1, \$217 and $\$ 221$ at port terminal 2, and \$210 and \$205 at port terminal 3, respectively.

\section{Conclusions}

The paper formulated a freight network model that captures decisions and interactions of ocean carriers and port terminal operators in the maritime freight transport system. Their hierarchical interactions were captured using a bilevel modeling approach. Numerical examples demonstrated the validity and applicability of the bilevel model.

Today, air pollution from international ships is a serious and urgent problem from perspectives of environmental destruction and health harm factors. Therefore, this study analyzed the effects of the environmental cost on ocean route choices by considering the emission cost of international container ships in addition to the general ocean transportation cost components. As a result, the optimal ocean routes and transportation costs were changed distinctively due to the different equilibrium conditions caused by the emission cost, compared with the case that does not consider the cost. Based on the relationships between ocean carriers and port terminal operators, port throughputs and operations were also changed accordingly. The results indicate that the emissions cost affects ocean routes directly and ocean shipping companies have to reflect this cost when making routing decisions to improve the current and future environment problems. The companies or relevant stakeholders can use the emission cost proposed in (1) and regard the emission cost as a key cost for calculating the transportation cost. The simulation results considering this new cost can provide new optimal strategies and reacting responses of competitors.

This study contributes to a freight network modeling approach considering the environmental cost, showing how the emission cost plays a role in ocean route changes. The research may be extended to a case with a different sum of the container flow and a more comprehensive study that finds the behavior of other stakeholders such as shippers and public bodies (i.e., Port Authorities) at the same time. Although this paper concentrated on the emissions of container ships, other types of ships like general cargo ships, barges, tankers, and so forth can be considered in future research. Also, the emission cost at marine ports and inland areas can be combined to analyze the impacts of emission costs extensively. 
TABLE 1: Engine power ratios and load factor assumptions.

\begin{tabular}{lcccc}
\hline \multirow{2}{*}{ Ship type } & \multirow{2}{*}{ AE to ME power ratio } & \multicolumn{3}{c}{ Load factor } \\
& & Cruise & RSZ & Maneuver \\
\hline Bulker/general cargo & 0.222 or 0.191 & 0.17 & 0.27 & 0.45 \\
Container & 0.220 & 0.13 & 0.25 & 0.50 \\
Passenger/ferry & 0.278 & 0.80 & 0.80 & 0.22 \\
Ro-Ro & 0.259 & 0.15 & 0.30 & 0.17 \\
Tanker & 0.211 & 0.13 & 0.27 & 0.45 \\
Miscellaneous & 0.257 & 0.17 & 0.27 & 0.45 \\
\hline
\end{tabular}

Sources: Work Shipping Encyclopedia, USEPA [20], and Yau et al. [22].

TABLE 2: Emission factors by sailing speed.

\begin{tabular}{lcccc}
\hline Engine type & Year built & $\mathrm{NO}_{x}$ & $\mathrm{SO}_{2}$ & \\
& & Main engine $(\mathrm{g} / \mathrm{kW})$ & 10.16 & \\
SSD & Before 2000 & 18.1 & 1.05 \\
SSD & After 2000 & 17 & 10.16 & 1.05 \\
MSD & Before 2000 & 14 & 10.16 & 1.11 \\
MSD & After 2000 & 13 & 10.16 & 1.11 \\
HSD & & 12.7 & 10.16 & 1.11 \\
\hline
\end{tabular}

Note: SSD: slow speed diesel; MSD: medium speed diesel; HSD: high speed diesel.

Sources: Entec [23], Lloyd's Register [24], USEPA [20], and Yau et al. [22].

\section{Appendix}

See Tables 3 and 4.

\section{Notations}

\section{(i) Ocean Carrier}

$O$ : Set of ocean carriers

$W$ : Set of ocean carrier $O-D$ pairs

$L^{o}$ : Set of ocean links

$P_{w}^{o}$ : Set of ocean paths for $O-D$ pair $w$

$o$ : Ocean carrier $(o \in O)$

$w$ : Ocean carrier $O-D$ pair $(w \in W)$

$l^{\circ}:$ Ocean link $\left(l^{o} \in L^{o}\right)$

$p^{o}$ : Ocean path $\left(p^{o} \in P_{w}^{o}\right)$
S: Set of port terminal operators

$V$ : Set of port terminal $O-D$ pairs

$L^{s}$ : Set of port links

$P_{v}^{s}$ : Set of port paths

$s:$ Port terminal operator $(s \in S)$

$v$ : Port terminal $O-D$ pair $(v \in V)$

$l^{s}:$ Port link $\left(l^{s} \in L^{s}\right)$

$p^{s}$ : Port path $\left(p^{s} \in P_{v}^{s}\right)$

Data and Parameters

$d_{w}^{o}: \quad$ Transportation demand for O-D pair $w$

$\mathrm{EC}_{w}^{p^{o}}$ : Emission cost on the ocean path $p^{o}$ connecting $O-D$ pair $w$

$\operatorname{vot}^{o}$ : Value of time of ocean carrier $o$

$\operatorname{vot}^{s}$ : Value of time of port terminal operator $s$

$\mathrm{tt}^{l^{\circ}}: \quad$ Average travel time on the ocean link $l^{\circ}$

$\mathrm{st}^{l^{\circ}}: \quad$ Average shift time on the ocean link $l^{\circ}$

$\mathrm{st}^{l^{s}}:$ Average service time on the port link $l^{s}$

$\operatorname{cap}^{l^{\circ}}$ : Capacity of the ocean link $l^{\circ}$

cap $^{l^{s}}$ : Capacity of the port link $l^{s}$

Variables

(i) Ocean Carrier

(ii) Port Terminal Operator 
TABLE 3: Parameters in the transpiration cost functions.

\begin{tabular}{|c|c|c|c|c|c|c|c|c|}
\hline Link & $\omega_{o}$ & $\omega_{1}$ & $\omega_{2}$ & $\mathrm{tt}$ & st & $\varepsilon_{o}$ & $\varepsilon_{1}$ & Capacity \\
\hline Ocean link $1\left(l^{0^{1}}\right)$ & 180 & 2.2 & - & 17.8 & - & - & - & 30,000 \\
\hline Ocean link $2\left(l^{0^{2}}\right)$ & 185 & 2.2 & - & 17.0 & - & - & - & 30,000 \\
\hline Ocean link $3\left(l^{0^{3}}\right)$ & 184 & 2.3 & - & 16.8 & - & - & - & 30,000 \\
\hline Ocean link $4\left(l^{0^{4}}\right)$ & 188 & 2.8 & - & 16.2 & - & - & - & 30,000 \\
\hline Ocean link $5\left(l^{0^{5}}\right)$ & 179 & 2.9 & - & 15.5 & - & - & - & 30,000 \\
\hline Ocean link $6\left(l^{0^{6}}\right)$ & 175 & 3.1 & - & 15.9 & - & - & - & 30,000 \\
\hline Ocean link $7\left(l^{0^{7}}\right)$ & 181 & 2.9 & - & 15.2 & - & - & - & 30,000 \\
\hline Ocean link $8\left(l^{0^{8}}\right)$ & 183 & 3.2 & - & 16.3 & - & - & - & 30,000 \\
\hline Ocean link $9\left(l^{0^{9}}\right)$ & 186 & 2.6 & - & 16.2 & - & - & - & 30,000 \\
\hline Ocean link $10\left(l^{1^{10}}\right)$ & 182 & 2.4 & - & 17.1 & - & - & - & 30,000 \\
\hline Ocean link $11\left(l^{l^{11}}\right)$ & 184 & 2.2 & - & 16.8 & - & - & - & 30,000 \\
\hline Ocean link $12\left(l^{12}\right)$ & 28 & 3.5 & 2.5 & - & 0.3 & 3.8 & 2 & 60,000 \\
\hline Ocean link $13\left(l^{13}\right)$ & 36 & 3.7 & 2.75 & - & 0.8 & 4.2 & 2 & 60,000 \\
\hline Ocean link $14\left(l^{14}\right)$ & 32 & 3.3 & 2.4 & - & 0.2 & 3.8 & 2 & 60,000 \\
\hline
\end{tabular}

TABLE 4: Parameters in the average port service cost function.

\begin{tabular}{|c|c|c|c|c|c|c|c|}
\hline Link & $\gamma_{o}$ & $\gamma_{1}$ & $\gamma_{2}$ & st & $\lambda_{o}$ & $\lambda_{2}$ & Capacity \\
\hline Port link $1\left(l^{0^{1}}\right)$ & 78 & 2.7 & 0.85 & 4.5 & 1.2 & 2 & 100,000 \\
\hline Port link $2\left(l^{0^{2}}\right)$ & 102 & 2.1 & 0.78 & 3.8 & 2.2 & 2 & 100,000 \\
\hline Port link $3\left(l^{0^{3}}\right)$ & 68 & 3.1 & 0.65 & 4.2 & 2.1 & 2 & 100,000 \\
\hline Port link $4\left(l^{0^{4}}\right)$ & 26 & 2.3 & 0.55 & 8.0 & 1.7 & 2 & 100,000 \\
\hline Port link $5\left(l^{0^{5}}\right)$ & 56 & 1.4 & 0.58 & 3.8 & 2.3 & 2 & 100,000 \\
\hline Port link $6\left(l^{0^{6}}\right)$ & 52 & 1.7 & 0.74 & 2.8 & 1.6 & 2 & 100,000 \\
\hline Port link $7\left(l^{0^{7}}\right)$ & 112 & 2.2 & 0.75 & 5.6 & 2.2 & 2 & 100,000 \\
\hline Port link $8\left(l^{l^{8}}\right)$ & 42 & 2.6 & 0.62 & 3.8 & 2.4 & 2 & 100,000 \\
\hline Port link $9\left(l^{0^{9}}\right)$ & 32 & 3.2 & 0.63 & 3.2 & 2.6 & 2 & 100,000 \\
\hline Port link $10\left(l^{l^{10}}\right)$ & 29 & 2.2 & 0.82 & 2.3 & 1.2 & 2 & 100,000 \\
\hline Port link $11\left(l^{0^{11}}\right)$ & 74 & 1.9 & 0.53 & 3.5 & 1.8 & 2 & 100,000 \\
\hline Port link $12\left(l^{l^{12}}\right)$ & 120 & 2.2 & 0.87 & 7.2 & 3.2 & 2 & 100,000 \\
\hline Port link $13\left(l^{l^{13}}\right)$ & 63 & 1.6 & 0.47 & 6.2 & 3.4 & 2 & 100,000 \\
\hline Port link $14\left(l^{l^{14}}\right)$ & 88 & 2.6 & 0.85 & 4.9 & 3.6 & 2 & 100,000 \\
\hline Port link $15\left(l^{l^{15}}\right)$ & 95 & 1.8 & 0.72 & 6.3 & 2.2 & 2 & 100,000 \\
\hline Port link $16\left(l^{l^{16}}\right)$ & 43 & 0.9 & 0.62 & 3.4 & 2.8 & 2 & 100,000 \\
\hline Port link $17\left(l^{l^{17}}\right)$ & 59 & 1.2 & 0.58 & 4.6 & 3.1 & 2 & 100,000 \\
\hline Port link $18\left(l^{l^{18}}\right)$ & 85 & 2.1 & 0.77 & 5.3 & 3.5 & 2 & 100,000 \\
\hline
\end{tabular}

$f_{w}^{o}: \quad$ Container volume of ocean carrier $o$ for $O-D$ pair $w$

$f_{w}^{p^{o}}$ : Container volume on the ocean path $p^{o}$ connecting $O-D$ pair $w$

$f^{l^{o}}:$ Container volume on the ocean link $l^{o}$

$\mu^{l^{o}, p^{o}}: 1$, if the ocean link $l^{o}$ is on the ocean path $p^{o}$; otherwise 0

$\pi^{o, p}: 1$, if the ocean carrier $o$ chooses port terminal operator $p$; otherwise 0

(ii) Port Terminal Operator $c^{s}: \quad$ The service charge of port terminal operator $s$

$c^{-s}$ : The service charges of other port terminal operators except port terminal operator $s$

$f_{v}^{s}: \quad$ Container volume of port terminal operators connecting $O-D$ pair $w$

$f_{v}^{p^{s}}$ : Container volume on the port path $p^{s}$ connecting $O-D$ pair $v$

$f^{l^{s}}: \quad$ Container volume on the port link $l^{s}$

$\varphi^{l^{s}, p^{s}}: 1$, if the port link $l^{s}$ is on the port path $p^{s}$; otherwise 0 
TABLE 5: Container flow changes in ocean links.

\begin{tabular}{|c|c|c|c|}
\hline Ocean link & Without emission cost & With emission cost & Difference $(A-B)$ \\
\hline Ocean link $1\left(l^{l^{1}}\right)$ & 13,506 & 1,506 & 12,000 \\
\hline Ocean link $2\left(l^{o^{2}}\right)$ & 4,740 & 1,740 & 3,000 \\
\hline Ocean link $3\left(l^{0^{3}}\right)$ & 2,680 & 32,680 & $-10,000$ \\
\hline Ocean link $4\left(l^{0^{4}}\right)$ & 11,724 & 12,724 & $-1,000$ \\
\hline Ocean link $5\left(l^{0^{5}}\right)$ & 6,810 & 6,310 & 500 \\
\hline Ocean link $6\left(l^{0^{6}}\right)$ & 29,670 & 40,070 & $-10,400$ \\
\hline Ocean link $7\left(l^{0^{7}}\right)$ & 4,319 & 1,019 & 3,300 \\
\hline Ocean link $8\left(l^{0^{8}}\right)$ & 19,277 & 28,977 & $-9,700$ \\
\hline Ocean link $9\left(l^{0^{9}}\right)$ & 13,902 & 14,902 & $-1,000$ \\
\hline Ocean link $10\left(l^{l^{10}}\right)$ & 12,536 & 8,536 & 4,000 \\
\hline Ocean link $11\left(l^{\mathrm{O}}\right)$ & 11,336 & 2,036 & 9,300 \\
\hline Ocean link $12\left(l^{l^{12}}\right)$ & 52,650 & 48,650 & 4,000 \\
\hline Ocean link $13\left(l^{0^{13}}\right)$ & 40,799 & 47,399 & $-6,600$ \\
\hline Ocean link $14\left(l^{\rho^{14}}\right)$ & 57,051 & 54,451 & 2,600 \\
\hline Total & 150,500 & 150,500 & - \\
\hline
\end{tabular}

TABLE 6: Profit changes of port terminal operators.

\begin{tabular}{lccc}
\hline Port terminal operator & Without & With & Difference $(A-B)$ \\
\hline Port terminal operator 1 & $15,795,000$ & $14,595,000$ & $-1,200,000$ \\
Port terminal operator 2 & $12,239,700$ & $14,219,700$ & $1,980,000$ \\
Port terminal operator 3 & $17,115,300$ & $16,335,300$ & $-780,000$ \\
\hline Total & $45,150,000$ & $45,150,000$ & - \\
\hline
\end{tabular}

TABLE 7: Container flow changes in port links.

\begin{tabular}{|c|c|c|c|c|}
\hline & Ocean link & Without & With & Difference $(A-B)$ \\
\hline \multirow{7}{*}{ Port terminal 1} & Port link $1\left(l^{1}\right)$ & 39,810 & 37,110 & 2,700 \\
\hline & Port link $2\left(l^{0^{2}}\right)$ & 14,260 & 12,560 & 1,700 \\
\hline & Port link $3\left(l^{l^{3}}\right)$ & 12,840 & 11,340 & 1,500 \\
\hline & Port link $4\left(l^{0^{4}}\right)$ & 25,550 & 24,550 & 1,000 \\
\hline & Port link $5\left(l^{0^{5}}\right)$ & 12,840 & 11,340 & 1,500 \\
\hline & Port link $6\left(l^{0^{6}}\right)$ & 38,390 & 35,890 & 2,500 \\
\hline & Total & 52,650 & 48,650 & 4,000 \\
\hline \multirow{6}{*}{ Port terminal 2} & Port link $7\left(l^{\circ}\right)$ & 22,530 & 26,035 & $-3,505$ \\
\hline & Port link $8\left(l^{0^{8}}\right)$ & 18,269 & 21,364 & $-3,095$ \\
\hline & Port link $9\left(l^{0^{9}}\right)$ & 18,269 & 21,364 & $-3,095$ \\
\hline & Port link $10\left(l^{o^{10}}\right)$ & 18,269 & 21,364 & $-3,095$ \\
\hline & Port link $11\left(l^{l^{11}}\right)$ & 40,799 & 47,399 & $-6,600$ \\
\hline & Total & 40,799 & 47,399 & $-6,600$ \\
\hline \multirow{8}{*}{ Port terminal 3} & Port link $12\left(l^{\mathrm{O}^{2}}\right)$ & 27,371 & 27,356 & 15 \\
\hline & Port link $13\left(l^{l^{13}}\right)$ & 27,371 & 27,356 & 15 \\
\hline & Port link $14\left(l^{o^{14}}\right)$ & 18,440 & 15,425 & 3,015 \\
\hline & Port link $15\left(l^{o^{15}}\right)$ & 18,440 & 15,425 & 3,015 \\
\hline & Port link $16\left(l^{l^{16}}\right)$ & 11,240 & 11,670 & -430 \\
\hline & Port link $17\left(l^{0^{17}}\right)$ & 11,240 & 11,670 & -430 \\
\hline & Port link $18\left(l^{0^{18}}\right)$ & 11,240 & 11,670 & -430 \\
\hline & Total & 57,051 & 54,451 & 2,600 \\
\hline Total & & 150,500 & 150,500 & - \\
\hline
\end{tabular}




\section{Functions}

\section{(i) Ocean Carrier}

$\mathrm{TC}_{w}^{o}$ : Transportation cost function of ocean carrier for $O-D$ pair $w$

$\mathrm{TC}_{w}^{p^{o}}$ : Transportation cost function of ocean path $p^{o}$ connecting $O-D$ pair $w$

$\mathrm{EC}_{w}^{p^{o}}$ : Emission cost function of ocean path $p^{o}$ connecting $O-D$ pair $w$

$\mathrm{TC}^{l^{\circ}}$ : Transportation cost function of ocean link $l^{o}$

$\mathrm{OC}^{l^{\circ}}$ : Operating cost function of ocean link $l^{o}$

$\mathrm{TT}^{l^{o}}$ : Travel (shift) time function of ocean link $l^{o}$

\section{(ii) Port Terminal Operator}

$U^{s}$ : Profit function of port terminal operator $s$

$G^{s}$ : Port throughput function of port terminal operator $s$

$\mathrm{SC}^{s}$ : Port service cost function of port terminal operator $s$

$\mathrm{SC}_{v}^{p^{s}}$ : Service cost function of the port path $p^{s}$ connecting $O-D$ pair $v$

$\mathrm{SC}^{l^{s}}$ : Port service cost function of the port link $l^{s}$

$\mathrm{ST}^{l^{s}}$ : Port service time function of the port link $l^{s}$.

\section{Competing Interests}

The authors declare that they have no competing interests.

\section{Acknowledgments}

This work was supported by Incheon National University Research Grant in 2015.

\section{References}

[1] Y. Zan, "Analysis of container port policy by the reaction of an equilibrium shipping market," Maritime Policy and Management, vol. 26, no. 4, pp. 369-381, 1999.

[2] K. Kuroda, M. Takebayashi, and T. Tsuji, "International container transportation network analysis considering postpanamax class container ships," Research in Transportation Economics, vol. 13, pp. 369-391, 2005.

[3] T. Zhang, Q. Zhao, and W. Wu, Bi-Level Programming Model of Container Port Game in the Container Transport Supernetwork, Korean Society for Computational and Applied Mathematics, 2008.
[4] H. Lee, M. Boile, and S. Theofanis, "Modeling carrier interactions in an international freight transport system," International Journal of Information Systems and Supply Chain Management, vol. 7, no. 1, pp. 15-39, 2014.

[5] H. Lee, M. Boile, S. Theofanis, and S. Choo, "Game theoretical models of the cooperative carrier behavior," KSCE Journal of Civil Engineering, vol. 18, no. 5, pp. 1528-1538, 2014.

[6] H. Lee, Y. Song, S. Choo, K.-Y. Chung, and K.-D. Lee, "Bi-level optimization programming for the shipper-carrier network problem," Cluster Computing, vol. 17, no. 3, pp. 805-816, 2014.

[7] Y. Wang, A bi-level programming approach for the shippercarrier network problem [Ph.D. thesis], New Jersey Institute of Technology, 2001.

[8] H. Min and Z. Guo, "Developing bi-level equilibrium models for the global container transportation network from the perspectives of multiple stakeholders," International Journal of Logistics Systems and Management, vol. 6, no. 4, pp. 362-379, 2010.

[9] X. Zhang, H. M. Zhang, H.-J. Huang, L. J. Sun, and T.-Q. Tang, "Competitive, cooperative and stackelberg congestion pricing for multiple regions in transportation networks," Transportmetrica, vol. 7, no. 4, pp. 297-320, 2011.

[10] G. S. Kim and T. S. Kim, "Functional networking of logistics port cities in Northeast Asia," International Journal of Urban Sciences, vol. 14, no. 1, pp. 73-85, 2011.

[11] L. Jiang and J. Kronbak, The Model of Maritime External Costs', Work Package, University of Southern Denmark, 2012.

[12] J. Berechman and P.-H. Tseng, "Estimating the environmental costs of port related emissions: the case of Kaohsiung," Transportation Research Part D: Transport and Environment, vol. 17, no. 1, pp. 35-38, 2012.

[13] P. S. Yau, S. C. Lee, Y. Cheng, Y. Huang, S. C. Lai, and X. $\mathrm{H}$. Xu, "Contribution of ship emissions to the fine particulate in the community near an international port in Hong Kong," Atmospheric Research, vol. 124, pp. 61-72, 2013.

[14] H. Saraçoğlu, C. Deniz, and A. Kılıç, "An investigation on the effects of ship sourced emissions in Izmir port, Turkey," The Scientific World Journal, vol. 2013, Article ID 218324, 8 pages, 2013.

[15] C. Deniz, A. Kilic, and G. Civkaroglu, "Estimation of shipping emissions in Candarli Gulf, Turkey," Environmental Monitoring and Assessment, vol. 171, no. 1, pp. 219-228, 2010.

[16] J. J. Corbett, H. Wang, and J. J. Winebrake, "The effectiveness and costs of speed reductions on emissions from international shipping," Transportation Research Part D: Transport and Environment, vol. 14, no. 8, pp. 593-598, 2009.

[17] K. Ahn and H. Rakha, "The effects of route choice decisions on vehicle energy consumption and emissions," Transportation Research Part D: Transport and Environment, vol. 13, no. 3, pp. 151-167, 2008.

[18] D. Park, N. S. Kim, H. Park, and K. Kim, "Estimating trade-off among logistics cost, $\mathrm{CO}_{2}$ and time: a case study of container transportation systems in Korea," International Journal of Urban Sciences, vol. 16, no. 1, pp. 85-98, 2012.

[19] A. Shukla and M. Alam, "Assessment of real world on-road vehicle emissions under dynamic urban traffic conditions in Delhi," International Journal of Urban Sciences, vol. 14, no. 2, pp. 207-220, 2011.

[20] USEPA, Current Methodologies and Best Practices in Preparing Port Emission Inventories, United States Environmental Protection Agency, 2006. 
[21] A. Nagurney, Network Economics: A Variational Inequality Approach, Kluwer Academic Publishers, Boston, Mass, USA, 1999.

[22] P. S. Yau, S. C. Lee, J. J. Corbett, C. Wang, Y. Cheng, and K. F. Ho, "Estimation of exhaust emission from ocean-going vessels in Hong Kong," Science of the Total Environment, vol. 431, pp. 299-306, 2012.

[23] Entec, "Qualification of emissions from ships associated with ship movements between ports in the European community," Final Report, Entec, Newcastle upon Tyne, UK, 2002.

[24] Lloyd's Register, Marine Exhaust Emissions Research Programme, Lloyd's Register, 1995. 


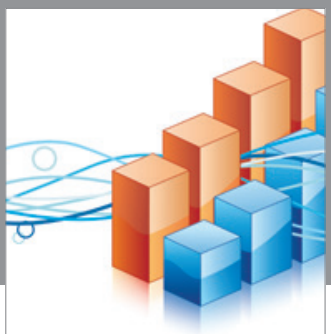

Advances in

Operations Research

vatem alat4

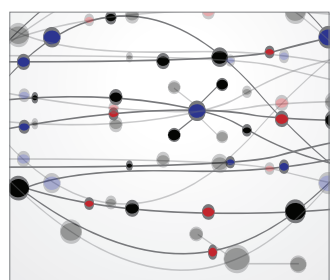

\section{The Scientific} World Journal
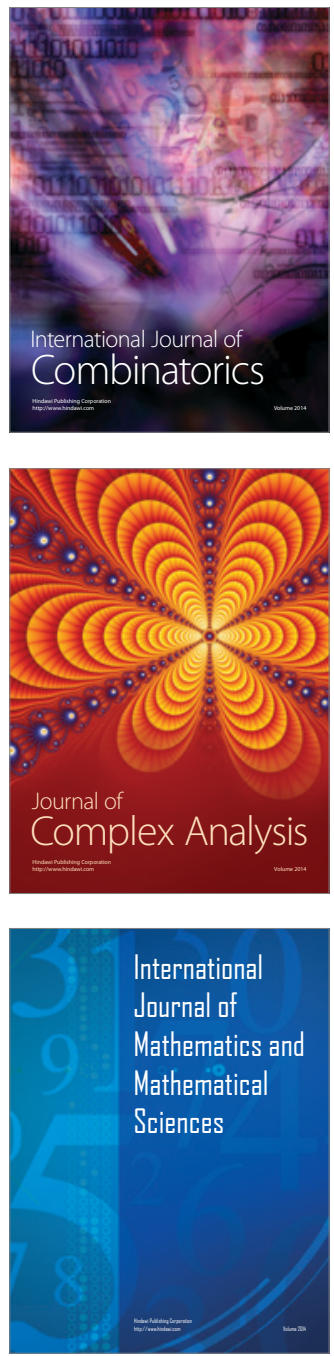
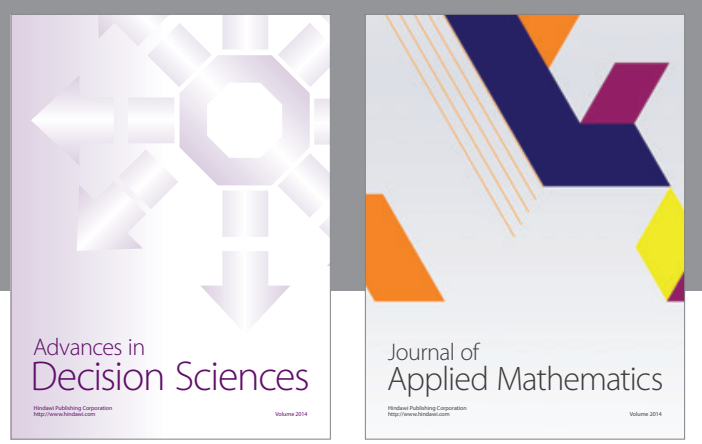

Algebra

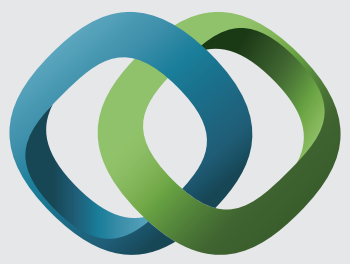

\section{Hindawi}

Submit your manuscripts at

http://www.hindawi.com
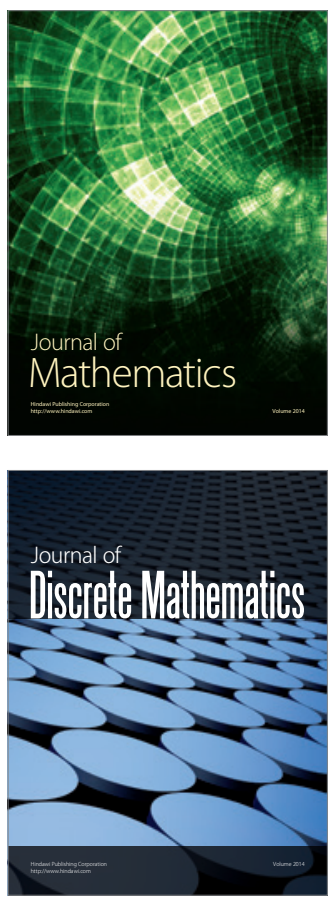

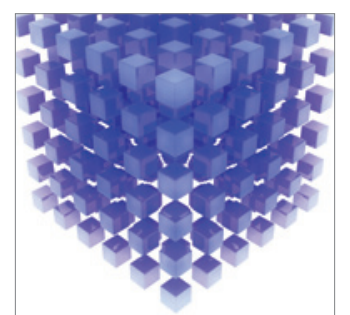

Mathematical Problems in Engineering
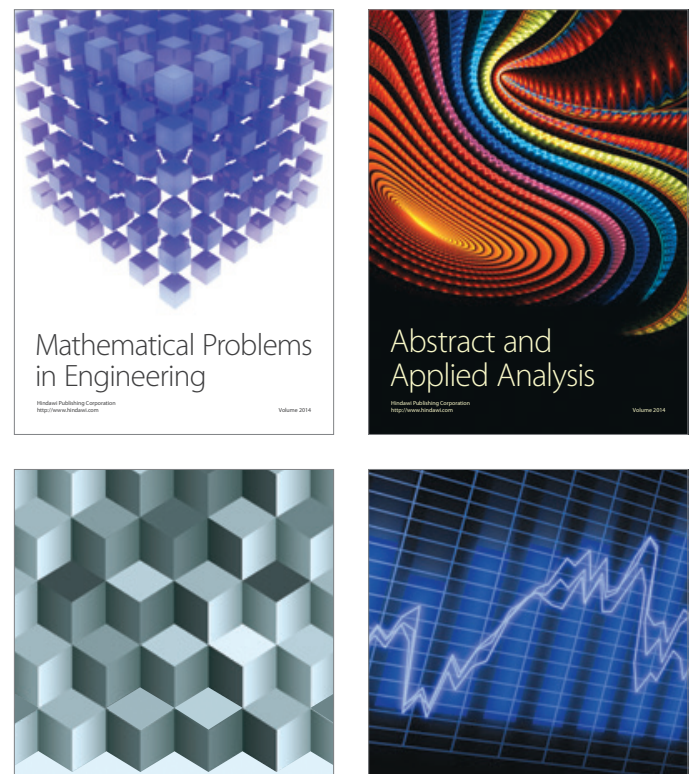

Journal of

Function Spaces

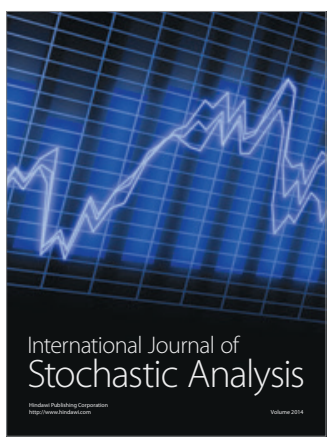

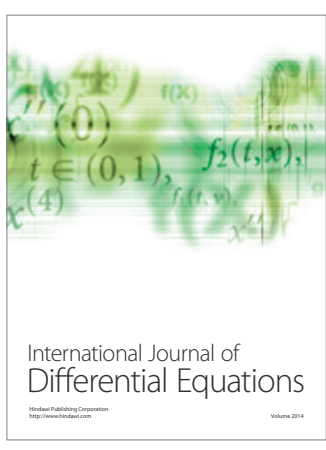
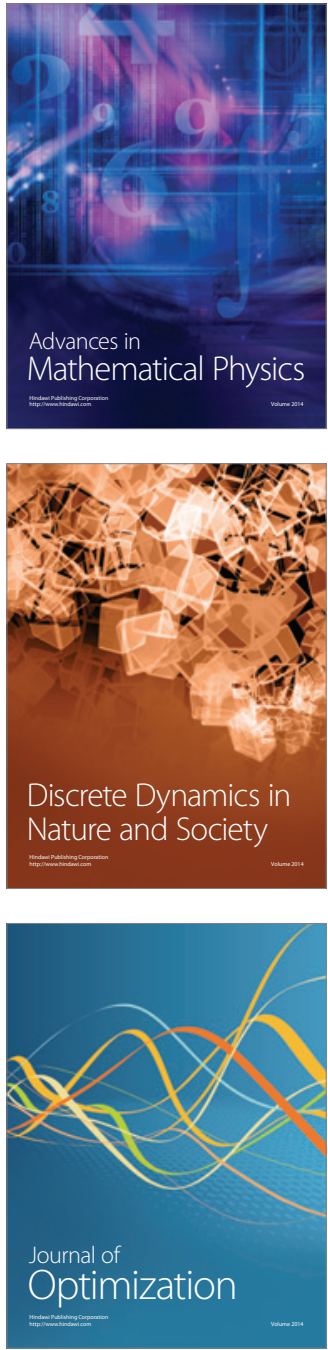